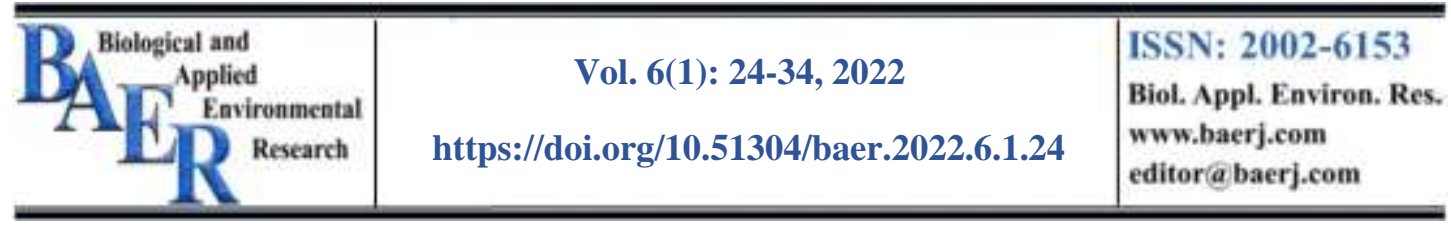

\title{
Noise Pollution Monitoring at Some Indoor Environments in Basrah City, Iraq
}

\author{
Inaam A.A. Qzar \\ Department of Ecology, College of Science, University of Basrah, Basrah, Iraq \\ *Corresponding author: inaam.abdulhusein@uobasrah.edu.iq
}

\begin{abstract}
Noise is an unavoidable stressor nowadays; it adversely affects human health and the ability to perform mental and complex tasks. Eight selected points representing home environment were sampled in urban zones, the indoor and outdoor noise levels in these residential areas were evaluated during the summer and winter seasons. Also, nine points in educational institute represented by the College of Science through its lecture halls, laboratories and corridors, to compare them with WHO limits of sound pressure levels, to assess the level of noise experienced by people in indoor closed environments. The current study results showed higher sound levels than required inside homes and educational places. For homes, the highest sound level was $73.9 \mathrm{~dB}$ during summer in the living room and the lowest was 42.1 in winter in the bedroom, while the highest sound level in the educational environment was $72.37 \mathrm{~dB}$ in summer and the lowest was $61.75 \mathrm{~dB}$ in winter. Exposure of individuals to high levels of noise in educational institutions and in their homes means longer hours of exposure to noise pollution, which will negatively affect their health. Thus there is a serious need nowadays to adopt suitable control to reduce noise pollution at indoor points.
\end{abstract}

Keywords: Noise pollution, Indoor environments, Sound level, Sound pressure, Basrah

\section{Introduction}

The civilized development for human beings harmed their environment and all the organisms living in it. Noise pollution is a result of technology and one of the important problems in cities around the world. It has adverse effects on the behavior and productivity of the organisms and the quality of life (Maisonneuve et al., 2010).

Noise may be deemed an atmospheric contaminant like gaseous and particulate contaminants (Chambers, 2005). It could be defined as the undesirable sound that causes inconvenience and lack of focusing. It is also defined as inconsistent voices mixture of unwanted continuity that causes disturbance to the recipient. Noise level is usually measured in decibel (dB) to express the sound level pressure. It represents the internationally 
known unit for measuring sound and noise intensity (Stansfeld \& Matheson, 2003).

Noise damages human health since it is not easy to recognize noise pollution. The human ear sensitivity gets automatically adjusted to the ambient level of sound, and any slow increases in the ambient level of sounds will be unnoticed (Pritam et al., 2014).

Focusing certain sound waves on the ear will not only damage the person auditory ability or causing noise-induced hearing impairment. Still, it can also cause physiological effects, headaches, insomnia, lack of sleep in addition to high blood pressure and increased heart rate, as well as interference with speech communication, affecting mental health and human performance (WHO, 1999; Evans \& Hygee, 2007; Zannin et al., 2013).

A ratio of $33.4 \%$ of the total civil complaints in the environmental field is counted for noise problems (Kim, 2013). Stansfeld et al. (2005) and Szalma \& Hancock (2011) showed that permanent exposure to noise can negatively affect children's awareness and affect the language skills and central processes of the brain also cause a lack of focusing and visual attention.

Noise significantly affects all the living environment, not only humans. Rheindt (2003) showed the negative impact of high noise on both the richness and the biological diversity of birds in areas close to motorways and their abundance in these areas compared to the areas of control which are free of car noise.

Measuring noise pollution has become necessary in recent times as a result of its widespread. Ordinary people can participate in it. Maisonneuve et al. (2009) relied on several citizens to monitor noise pollution in their areas by linking them to the network through 'noise tube' site, which was created to help participants entering data into this network, monitoring the noise levels in their cities and drawing a map of it by downloading an application that turns the phone into a sound level measuring device.

Increasing people's awareness of the dangerous effects of noise pollution can effectively solve this problem. Singh \& Joshi (2012) found that noise pollution decreased in the last three years of their study, recording the lowest noise levels in 2009 compared to 2008 and 2007. According to them, the main reason for this is the increase of cultural and scientific awareness of the inhabitants of their city.

Noise sources can be divided into indoor and outdoor sources. Outdoor sources include workshops, transportation and roads noise. Indoor sources of noise pollution include social noise caused by individuals and noise from various household devices such as TV, hair dryer and others (Farid et al., 2013).

Some previous studies in the city of Basrah (Al-Hassen, 2013; Qzar et al., 2020) dealt with noise pollution in educational environments and 
concluded that there are noise levels higher than the accepted limits. While Karem et al. (2016) studied the noise level in West Qurna field in Basrah, which represents an industrial environment, and by comprising their results with standard levels, they found that sound level for this field lies within the recommended guidelines.

This study aimed to assess the level of noise experienced by people in closed indoor environments as an important factor impacting life type since outdoor noise sources can be avoided and kept away from them. Also, it aimed to recognize whether the sources of that indoor noise are induced from the outside or original from the inside.

\section{Materials and Methods}

Digital sound level meter type SL-814 (range: 40-130 dB) was used to estimate the volume of sounds in two indoor environments; houses and educational institutes.

Eight houses in five residential areas were selected for this study. Their areas ranged from 150 to $200 \mathrm{~m}^{2}$. They had common points; all are distant from industrial and commercial areas and motorways and family members ranged from five to seven persons for each, and having the same standards of living. Measurements were taken in summer and winter seasons, during three periods at the day; morning, afternoon and night, with five replicates for each period.

Measurements were recorded in the houses for each room and the outdoor by three repeats at different times of the day, taking into account the accuracy of the measurement in terms of avoiding air currents, choosing the location of the measure in the centre of the room, and neglecting the wrong readings. The sound pressure level measurements of several electrical household appliances taking three different repeaters per device were also performed within one meter from the device.

Educational environments readings were recorded three times for each of the twelve points. All the results were tested using SPSS statistics version 22 , under $5 \%$ significant degree.

\section{Results}

The current study showed a difference in the sound level between the rooms of different houses, where the highest value $(73.9 \mathrm{~dB})$ was for the living room in the summer. In comparison, the least $(42.1 \mathrm{~dB})$ was recorded in the bedroom in winter (Table 1). Readings in summer were markedly higher than them in winter (Figure 1). 
Table 1: Sound pressure level $(\mathrm{dB})$ in some houses indoor and outdoor environments.

\begin{tabular}{|c|c|c|c|c|c|c|c|}
\hline \multirow{2}{*}{ House } & \multirow{2}{*}{ Room } & \multicolumn{2}{|c|}{ Sound pressure level } & \multirow{2}{*}{ House } & \multirow{2}{*}{ Room } & \multicolumn{2}{|c|}{ Sound pressure level } \\
\hline & & Summer & Winter & & & Summer & Winter \\
\hline \multirow{4}{*}{1} & Bedroom & $51 \pm 1.5$ & $44 \pm 2.8$ & \multirow{4}{*}{5} & Bedroom & $52.6 \pm 2$ & $46.2 \pm 6.5$ \\
\hline & $\begin{array}{c}\text { Living } \\
\text { room }\end{array}$ & $73.9 \pm 2.4$ & $54.1 \pm 5.6$ & & $\begin{array}{c}\text { Living } \\
\text { room }\end{array}$ & $66.5 \pm 3.5$ & $57.9 \pm 8.5$ \\
\hline & Kitchen & $57.9 \pm 4.4$ & $52.7 \pm 5.6$ & & Kitchen & $59.7 \pm 2.5$ & $52.2 \pm 2.8$ \\
\hline & Outdoor & $59.6 \pm 3.3$ & $51.7 \pm 2.1$ & & Outdoor & $60.1 \pm 1.6$ & $51 \pm 4.3$ \\
\hline \multirow{4}{*}{2} & Bedroom & $55 \pm 3.69$ & $45.3 \pm 2.68$ & \multirow{4}{*}{6} & Bedroom & $56 \pm 0.6$ & $42.8 \pm 3$ \\
\hline & $\begin{array}{c}\text { Living } \\
\text { room }\end{array}$ & $56.6 \pm 3.2$ & $52.5 \pm 2.25$ & & $\begin{array}{c}\text { Living } \\
\text { room }\end{array}$ & $64.3 \pm 4.2$ & $59.1 \pm 5$ \\
\hline & Kitchen & $59.3 \pm 2.4$ & $51.9 \pm 3.1$ & & Kitchen & $66.3 \pm 1$ & $60.5 \pm 1.4$ \\
\hline & Outdoor & $59.8 \pm 3.8$ & $52 \pm 2.8$ & & Outdoor & $60 \pm 2$ & $55.1 \pm 4$ \\
\hline \multirow{4}{*}{3} & Bedroom & $52.3 \pm 5.8$ & $54.8 \pm 11.6$ & \multirow{4}{*}{7} & Bedroom & $52.7 \pm 3.2$ & $42.7 \pm 2.8$ \\
\hline & $\begin{array}{c}\text { Living } \\
\text { room }\end{array}$ & $68.1 \pm 11.7$ & $60.6 \pm 10.7$ & & $\begin{array}{c}\text { Living } \\
\text { room }\end{array}$ & $67.7 \pm 6.5$ & $66.5 \pm 3.5$ \\
\hline & Kitchen & $61.6 \pm 13.1$ & $59.8 \pm 13.3$ & & Kitchen & $66.3 \pm 1$ & $59.9 \pm 1.3$ \\
\hline & Outdoor & $62.3 \pm 7.4$ & $57.3 \pm 6.8$ & & Outdoor & $61 \pm 2.6$ & $55.5 \pm 4.2$ \\
\hline \multirow{4}{*}{4} & Bedroom & $54.4 \pm 9.4$ & $61.1 \pm 9.4$ & \multirow{4}{*}{8} & Bedroom & $44.3 \pm 3.7$ & $42.1 \pm 2$ \\
\hline & $\begin{array}{c}\text { Living } \\
\text { room }\end{array}$ & $66.1 \pm 10.8$ & $58.4 \pm 8.6$ & & $\begin{array}{c}\text { Living } \\
\text { room }\end{array}$ & $69.9 \pm 4.4$ & $58.6 \pm 2.7$ \\
\hline & Kitchen & $62 \pm 12.6$ & $61.1 \pm 9.4$ & & Kitchen & $58.5 \pm 1.3$ & $51.7 \pm 3.5$ \\
\hline & Outdoor & $62.2 \pm 10.4$ & $54.1 \pm 10.4$ & & Outdoor & $59.8 \pm 2.3$ & $55 \pm 4.39$ \\
\hline
\end{tabular}

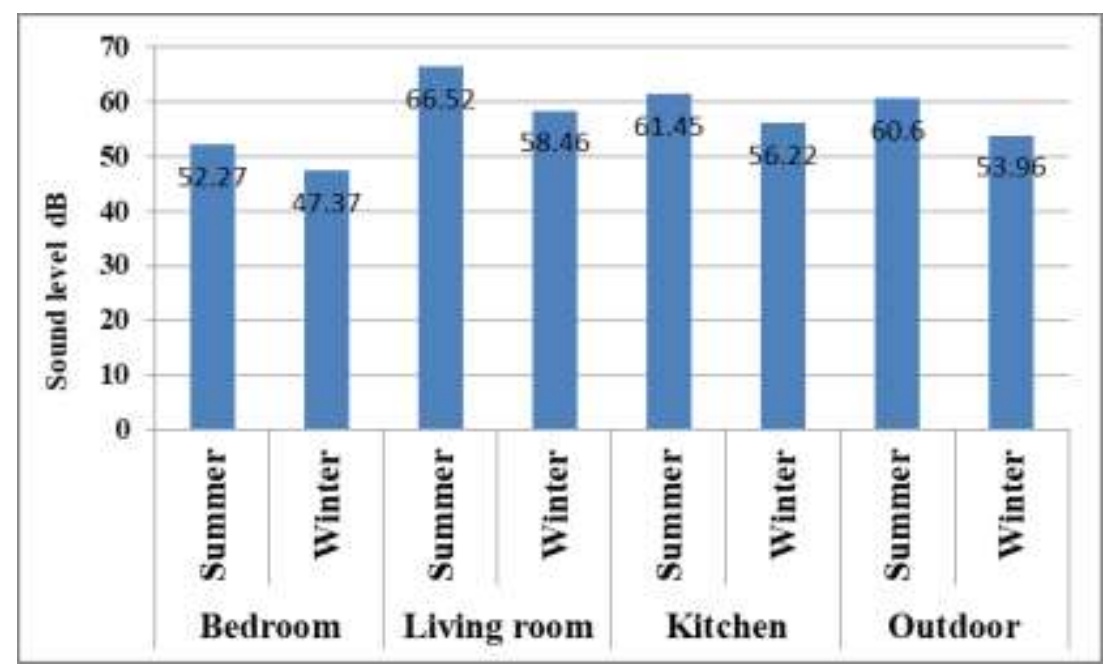

Figure 1: difference in sound level between summer and winter seasons in houses indoor environment. 
Differences in the sound levels among the different halls of the educational environment were recorded, where the highest value was $72.37 \mathrm{~dB}$ for the lecture halls in summer and the lowest was $61.75 \mathrm{~dB}$ in laboratories at winter. The readings in summer were markedly higher than they were in winter for educational environments (Figure 2).

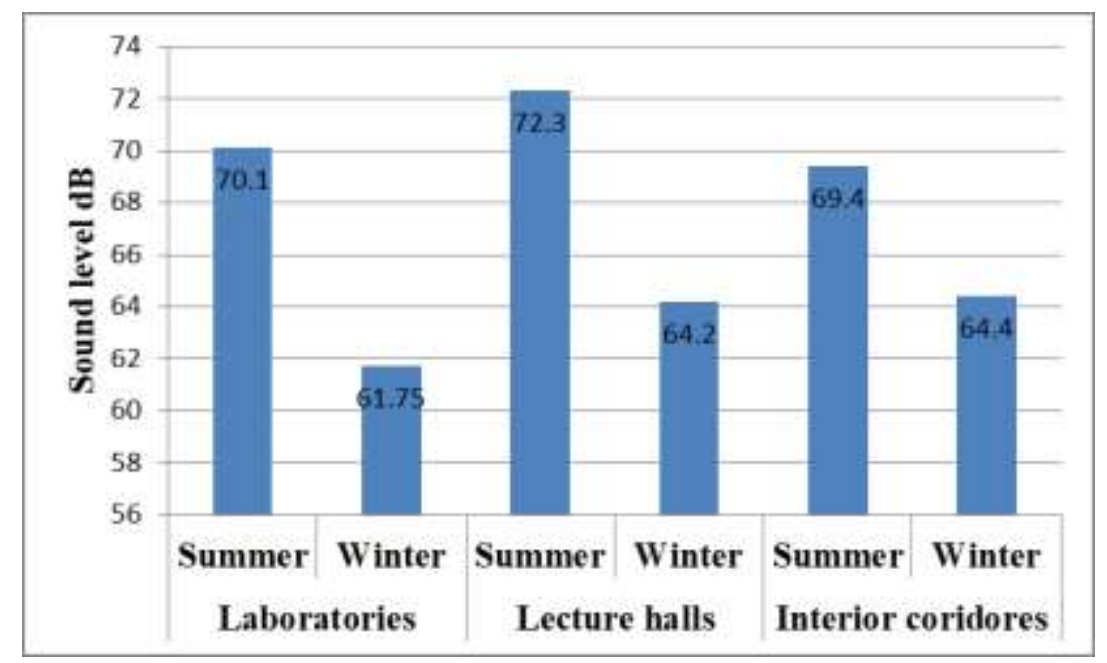

Figure 2: difference in sound level between summer and winter seasons at the indoor educational environment.

There were no significant differences $(\mathrm{P}>0.05)$ between the living room and the kitchen with the outdoor, while the bedroom significantly differs from other rooms (Figure 3). For the indoor educational environment, there were no significant differences (Figure 4).

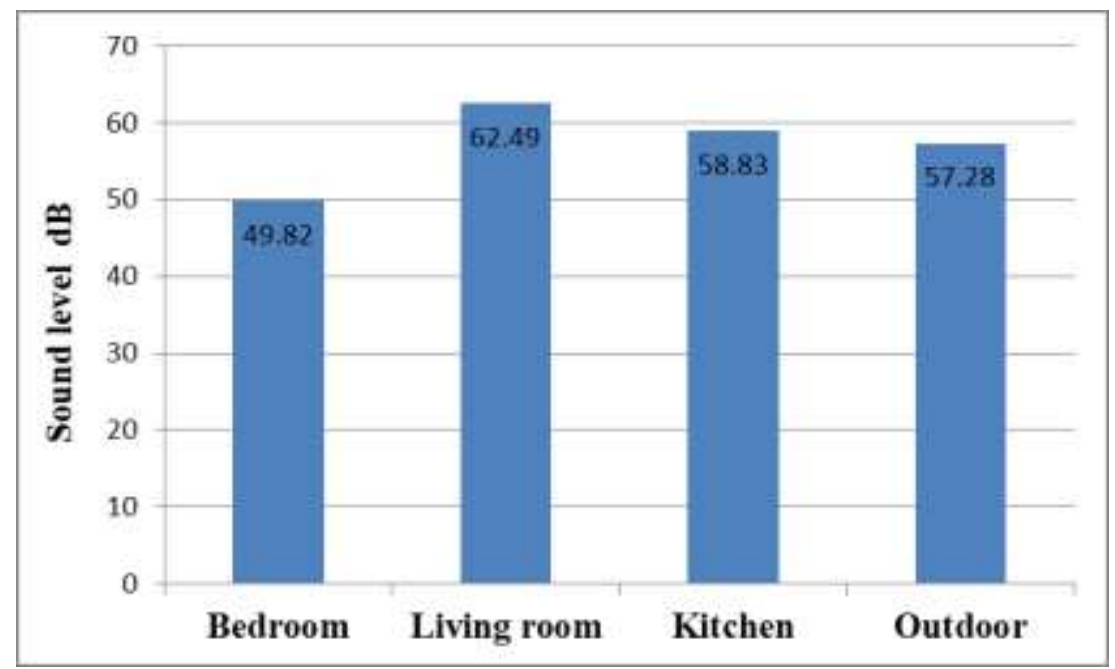

Figure 3: Differences in sound level among different rooms of the house. 


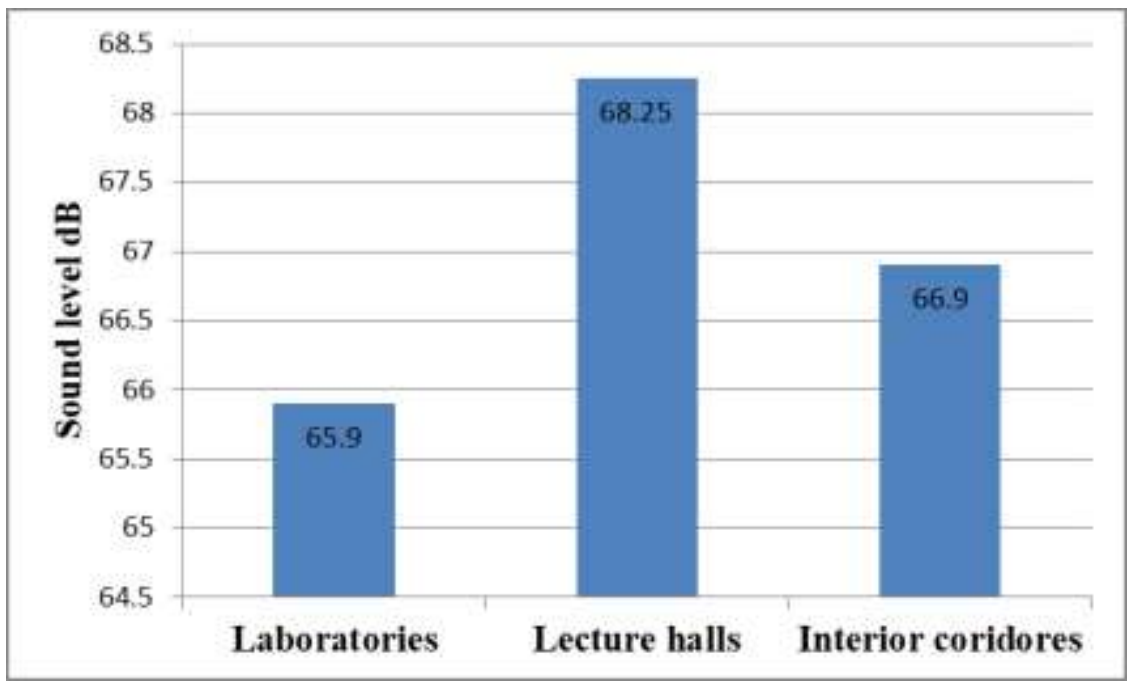

Figure 4: Differences in sound level between different halls of the educational environment.

These results showed that educational halls recorded a significant higher level of sound, and there were a big difference between home and indoor educational environments, which recorded significantly higher sound levels during summer and winter in its halls (Figure 5).

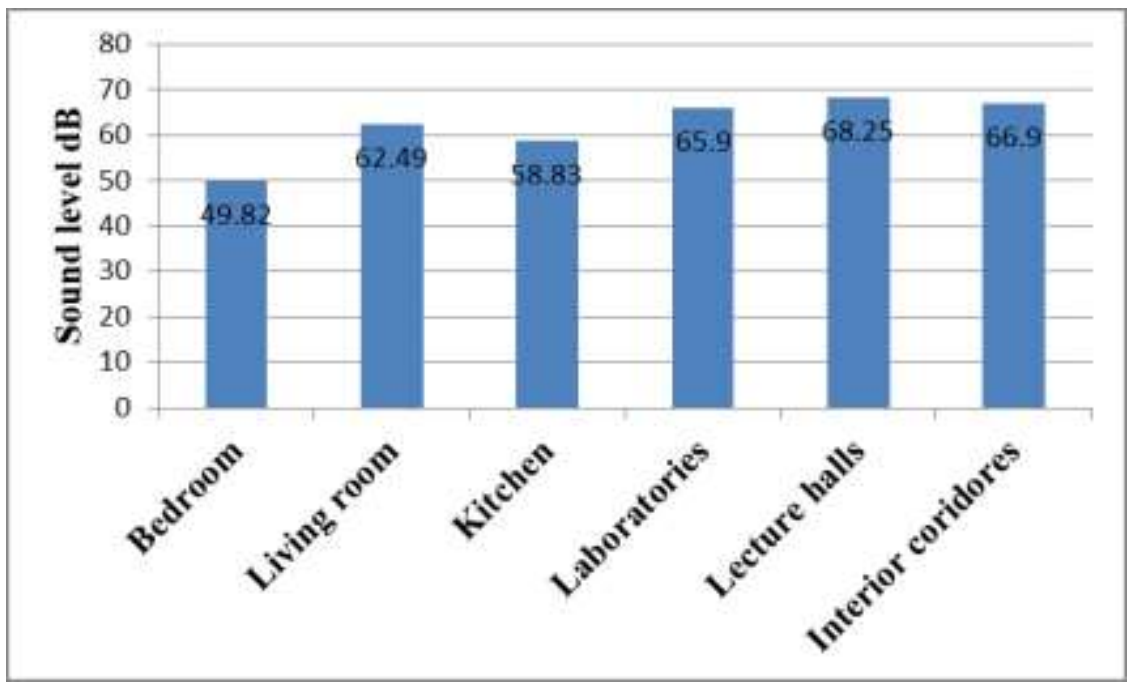

Figure 5: Sound level difference between home and indoor educational environments.

The current results have shown that household electrical appliances significantly influence sound levels in home interior environments in terms of additional noise sources for indoor environments (Table 2). 
Table 2: Measurements of sound pressure levels $(\mathrm{dB})$ for some devices indoor used.

\begin{tabular}{|l|c|}
\hline \multicolumn{1}{|c|}{ Device } & Sound pressure level $(\mathrm{dB})$ \\
\hline Ceiling fan & 51.566 \\
\hline Hair dryer & 81.133 \\
\hline Mixer & 82.8 \\
\hline Split units & 53.7 \\
\hline Other air conditioning & 63.1 \\
\hline TV & 58.5 \\
\hline Vacuum cleaner & 101 \\
\hline Air-tight & 64 \\
\hline Tugs & 63 \\
\hline Fridge & 53.5 \\
\hline Kid toys & 68 \\
\hline Washing machine & 66.2 \\
\hline Freezer & 50 \\
\hline
\end{tabular}

\section{Discussion}

Through the results of the current study, it was noticed that there is a significant difference between the sound levels during the summer and its levels in winter, where the readings in the summer were higher than in winter due to the frequent use of air conditioners, fans, generators and other noise-causing devices, in addition to the fact that people are more active in the summer

The highest readings were in the living room due to the presence of a $\mathrm{TV}$, and a large number of people present in it compared to the rest of the rooms of the house. While the least were in the bedroom due to the lack of noise-causing devices in it. The readings of the kitchen room were also high because of the presence of many electrical devices that export sounds in it such as the air puller, refrigerator and others. However, Singh \& Dev (2010) considered that damage resulting from continuous noise exposure might be eliminated when this exposure becomes a type of adaptation in people's life.

According to these results, one can say that indoor noise is self-induced, especially when taking in consideration that outdoor sound levels recorded less than in the living room and the kitchen in almost all the studied houses with no significant differences between them. This could be due to the wide use of different household appliances. Noise from residential events, whether indoor or outdoor, may not seem like much or very important at first, but when taking in consideration air conditioners, kitchen appliances, dishwashers, washing machines, televisions, stereos, children and pets, the general impact of these sources cannot be ignored. Moreover, a small 
increase in the number of tools, cars and devices used by modern industrial societies can create a significant noise burden.

Part of the problems facing the researchers to determine noise damages is the interaction between human, health, noise and disease is complex and cannot be easily measured because man is not a negative recipient of noise. A human can avoid exposure to it or minimize its impact on him in different ways, in addition to the difference in ear sensitivity from one person to another. Therefore, identifying the type of harm that noise can cause to health cannot be measured precisely (Stansfeld \& Meatheson, 2003).

The level of sound in the studied houses was unacceptable and noisy according to NBR 10152:1987 (Associação Brasileira de Normas Técnicas, 1987), the Federal Environmental Protection Agency (FEPA, 1995) and World Health Organization (WHO, 1999).

According to standard NBR 10151:2000, sound levels at daytime in strictly urban (houses and school areas) should be about $50 \mathrm{~dB}$. In contrast, it ranged from 35-50 dB for houses and 40-55 dB in the educational environment, according to Kinsler et al. (2000) and NBR 10152:1987 (Zannin \& Ferraz, 2016).

Table 3: Noise levels according to NBR 10152:1987 (Zannin \& Ferraz, 2016).

\begin{tabular}{|l|c|c|}
\hline \multicolumn{2}{|c|}{ Specific environment } & Sound pressure level $(\mathrm{dB})$ \\
\hline \multirow{2}{*}{ Houses } & Bedrooms & $35-45$ \\
\cline { 2 - 3 } & Living rooms & $40-50$ \\
\hline \multirow{2}{*}{ Educational environments } & Lecture halls and laboratories & $40-50$ \\
\cline { 2 - 3 } & Circulation areas & $45-55$ \\
\hline
\end{tabular}

Table 4: WHO guideline values for community noise in specific indoor environments (FEPA, 1995; WHO, 1999).

\begin{tabular}{|l|c|c|}
\hline \multicolumn{2}{|c|}{ Specific environment } & Sound pressure level (dB) \\
\hline \multirow{2}{*}{ Houses } & Bedrooms & $35-50$ \\
\cline { 2 - 3 } & Living rooms & $35-50$ \\
\hline
\end{tabular}

It is very important to notice that by comparing the sound level inside and outside the home environment, one finds that the internal noise sources were mostly induced from the inside because the sound level at the same time of measurement is lower in outside the house.

Qzar et al. (2020) reached the same conclusion in their study, as it showed that the levels of noise in the indoor environment of primary and intermediate schools were higher than the permissible level. So, a broad segment of society, represented by the school and university students besides the employees of these institutions, is exposed to longer hours of exposure to noise pollution in these environments and their houses, which, together, may adversely affect their health. 
In conclusion, noise has adverse effects on the productivity and behavior of man besides physiological effects such as headaches, insomnia and lack of sleep. Indoor environments of this study had higher sound pressure levels than permissible levels by the World Health Organization; records in summer were markedly higher than in winter. The noise sources were internally induced due to the increased use of tools and household devices used by modern industrial societies, which create a significant noise burden. Reduction of high noise in houses must be achieved by reducing the sound of the TV and other devices available in indoor environments, besides switching or repairing old appliances that may make annoying noises and negatively affect human beings. Reduce presence in places with high noise and increase awareness about noise harm.

\section{Acknowledgements}

The author would like to thank all the families who helped to complete this research by generously opening their houses for measurement. I would also like to thank the College of Science in its various departments for allowing readings to be taken in various facilities of the college.

\section{References}

Al-Hassen, S. (2013). An assessment of noise pollution and associated health impacts at selected schools in Basra City, Southern Iraq. J. Basrah Res. (Sci.), 39(4B): 19-31. (In Arabic).

Associação Brasileira de Normas Técnicas (ABNT) (1987). NBR-10.152: Níveis de ruído para conforto acústico [Sound levels for acoustic comfort]. Rio de Janeiro. In: Zannin, P.H.T. \& Ferraz, F. (2016). Assessment of indoor and outdoor noise pollution at a university hospital based on acoustic measurements and noise mapping. Open J. Acoustics, 6: 71-85. (In Portuguese). http://www.scirp.org/journal/oja.

Chambers, J.P. (2005). Noise pollution. In: Wang, L.K.; Pereira, N.C. \& Hung, Y.T. (eds.). Advanced air and noise pollution control. Humana Press, Inc., Totowa, NJ: 441-452.

Evans, G.W. \& Hygge, S. (2007). Noise and cognitive performance in children and adults. In: Luxon, L. \& Prasher, D. (eds.). Noise and its effects. John Wiley, Chichester: 549-566.

Farid, M.; Ali, S.; Shakoor, M.B.; Azam, A.; Ehsan, S.; Tauqeer, H.M. \& Iftikar, U. (2013). Comparative study of noise levels in various areas of Faisalabad, Pakistan. Greener J. Environ. Manage. Public Safety, 2(4): 166-171. DOI:10.15580/GJEMPS.2013.4.062413686.

Federal Environmental Protection Agency (1995). Guidelines and standard for environmental pollution control in Nigeria (FEPA), Abuja. In: Otutu, O.J. (2011). Investigation of environmental noise within campus 2, Delta State University, Abraka, Nigeria. IJRRAS, 6(2): 223-229. 
Karem, D.S.; Kadhim, H.A. \& Al-Saad, H.T. (2016). Assessment of noise pollution in West Qurna-2 oil field Southern Iraq. J. Sci. Eng. Res., 3(5): 95-100.

Kim, B.J. (2013). The main policy directions for promoting living environment management. Bull. Korea Environ. Preservation Assoc., 408: 9-11.

Kinsler, L.E.; Frey, A.R.; Coppens, A.B. \& Sanders, J.V. (2000). Fundamentals of acoustics, $4^{\text {th }}$ edition, Wiley, New York: 560 pp.

Maisonneuve, N.; Stevens, M.; Niessen, M.E.; Hanappe, P. \& Steels, L. (2009). Citizen noise pollution monitoring. Proc. $10^{\text {th }}$ Int. Digital Gov. Res. Conf.: 8 pp. DOI:10.13039/501100000780.

Maisonneuve, N.; Stevens, M.L.L. \& Ochab, B. (2010). Participatory noise pollution monitoring using mobile phones. Inf. Polity, 15(1 \& 2): 51-71. DOI:10.3233/IP-2010-0200.

Pritam, U.; Pandey, G. \& Singh, S.P. (2014). Assessment of outdoor and indoor noise pollution in commercial areas of Gorakhpur City. Int. J. Eng. Res. Technol., 3(12): 777-783.

Qzar, I.A.; Azeez, N. \& Alkinani, S. (2020). The impact of noise pollution on schools students of Basra City, Iraq: A health study. EurAsian J. BioSci., 14(2): 5197-5201.

Rheindt, F.E. (2003). The impact of roads on birds: Does song frequency play a role in determining susceptibility to noise pollution? J. Ornithol., 144: 295306.

Singh, D. \& Joshi, B.D. (2012). Study of noise pollution for three consecutive years during Deepawali festival in Meerut City, Uttar Pradesh (India). J. Environ. Sci. Eng., 54(3): 413-415.

Singh, V. \& Dev, P. (2010). Environmental impacts of noise pollution: A case study of Saharanpur City, Western Uttar Pradesh, India. Int. J. Earth Sci. Eng., 3(6): 869-874.

Stansfeld, S.A. \& Matheson, M.P. (2003). Noise pollution: Non-auditory effects on health. Br. Med. Bull., 68(1): 243-257. DOI:10.1093/bmb/ldg033.

Stansfeld, S.A.; Berglund, B.; Clark, C.; Lopez-Barrio, I.; Fischer, P.; Ohrström, E.; Haines, M.M.; Head, J.; Hygge, S.; van Kamp, I. \& Berry, B.F. (2005). Aircraft and road traffic noise and children's cognition and health: A crossnational study. Lancet, 365(9475): 1942-1949. DOI:10.1016/S01406736(05)66660-3.

Szalma, J.L. \& Hancock, P.A. (2011). Noise effects on human performance: A meta-analytic synthesis. Psychol. Bull., 137(4): 682-707. DOI:10.1037/ a0023987.

WHO (1999). Guidelines for community noise. WHO expert task force meeting on guidelines for community noise, 26-30 April 1999, London. World Health Organization: $141 \mathrm{pp}$.

Zannin, P.H.T. \& Ferraz, F. (2016). Assessment of indoor and outdoor noise pollution at a university hospital based on acoustic measurements and noise mapping. Open J. Acoustics, 6(4): 71-85. DOI:10.4236/oja.2016.64006. 
Zannin, P.H.T.; Engel, M.S.; Fiedler, P.E.K. \& Bunn, F. (2013). Characterization of environmental noise based on noise measurements, noise mapping and interviews: A case study at a university campus in Brazil. Cities, 31: 317-327. DOI:10.1016/j.cities.2012.09.008. 